\title{
Crystallization at Solvent Interfaces Enables Access to a Variety of Cocrystal Polymorphs and Hydrates
}

\author{
Stefan J. Diez, ${ }^{\S}$ Mark D. Eddleston, ${ }^{\S}$ Mihails Arhangelskis, ${ }^{\S}$ Marie Milbled, ${ }^{\S}$ Matthias J. Müller, ${ }^{\S}$ \\ Andrew D. Bond, ${ }^{\S}$ Dejan-Krešimir Bučar, ${ }^{\dagger} * *$ and William Jones ${ }^{\S, *}$ \\ ${ }^{\S}$ Department of Chemistry, University of Cambridge, Lensfield Road, Cambridge CB2 1EW, U.K. \\ ${ }^{\dagger}$ Department of Chemistry, University College London, 20 Gordon Street, London WC1H 0AJ, U.K.
}

Supporting Information Placeholder

\begin{abstract}
A crystal growth technique, interfacial cocrystallization, is demonstrated to be a simple and effective method for preparing multi-component crystal forms. The technique is based on the generation of a liquid-liquid interface between two immiscible solutions of cocrystal-forming compounds, and its utility is demonstrated through the preparation of polymorphs and hydrates of caffeine cocrystals, involving three different hydroxy-2-naphthoic acids, including the formation of some with unexpected compositions.
\end{abstract}

\section{Introduction}

Multi-component crystals are widely utilized for crystal engineering purposes in a variety of settings, including the pharmaceutical industry. ${ }^{1}$ Cocrystals, which consist of at least two different types of neutral molecules (coformers) held together by non-covalent interactions (such as hydrogen bonds), play an increasingly important role in drug development owing to their capacity to enhance relevant chemical and physical properties of drug molecules in the solid $\operatorname{state}^{2}$ (e.g. chemical stability, ${ }^{3}$ hygroscopicity, ${ }^{4}$ tabletability ${ }^{5}$ or taste $\left.^{6}\right)$. The mounting number of patents and new FDAapproved medicines ${ }^{7}$ based on pharmaceutical cocrystals also attest to their potential and usefulness. Cocrystals are, however, prone to polymorphism like all other types of molecular crystals, ${ }^{8-9}$ and as a result it is essential to screen thoroughly for polymorphic forms of cocrystals during product development. ${ }^{10}$

To date, various techniques have been developed for the preparation of cocrystals on a laboratory scale, ${ }^{11-16}$ with the majority being solvent based (e.g. solvent evaporation and solvent cooling $\left.{ }^{17-18}\right)$. Solvent-based methods avoid partial degradation of drug molecules during cocrystallization, which may occur in the use of thermal methods such as cocrystallization from the melt. ${ }^{19} \mathrm{~A}$ drawback of solution growth, however, is the high risk of precipitating the pure components because of their potentially significant solubility differences, ${ }^{20}$ or the undesired formation of solvates. ${ }^{21}$ To avoid this issue, methods that employ less or even no liquid solvents (such as grinding, ${ }^{22}$ liquid-assisted ${ }^{11}$ and polymerassisted grinding, ${ }^{23}$ and slurrying ${ }^{24}$ ) have been devised and applied.

We applied the approach of crystallisation at solvent interfaces to the cocrystallization of phenazine and mesaconic acid in an earlier study, resulting in the generation of a novel monohydrate cocrystal form. ${ }^{20}$ Here we report the results of a systematic study that aimed to explore how precipitation at the boundary between two immiscible solutions containing the coformer molecules, a technique referred to as interfacial cocrystallization (IC), is a very effective screening method (Scheme 1).

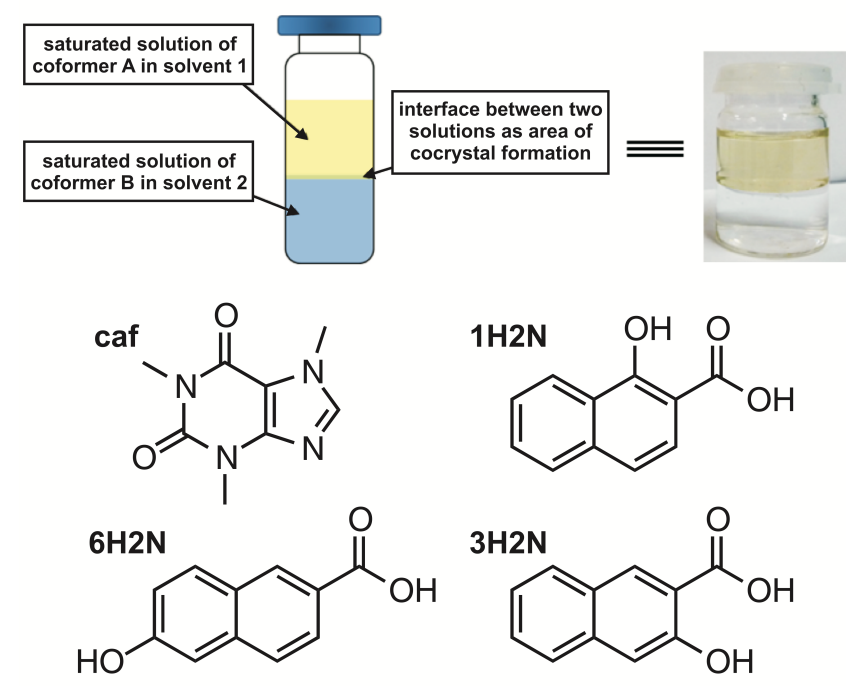

Scheme 1. Representation of an interfacial cocrystallization experiment whereby two saturated solutions of coformers in immiscible solvents are prepared separately and then combined (providing an interface at which cocrystallization can occur) (top); and molecular structures of caf, $1 \mathbf{H 2 N}$, 3H2N and 6H2N (bottom). 
Recognising the numerous studies that report the use of solvent interfaces to precipitate or crystallize various organic and inorganic species, ${ }^{25-29}$ this study focusses on the preparation of pharmaceutical cocrystals at solvent interfaces and highlights in particular the large number of experimental variations that are possible..

Using caffeine (caf) and hydroxy-2-naphthoic acids $(\mathbf{x H 2 N s})$ as model compounds, we show that IC enables fast access to a variety of polymorphs, hydrates of pharmaceutical cocrystals, as well as to cocrystal forms with atypical stoichiometric ratios. We further demonstrate how the chemical nature of the solvents, solution concentrations, various cocrystallization rates and the surrounding ambient temperatures affect the crystallization outcome. We also highlight several key advantages of the IC approach, namely the ability to screen multiple potential coformers simultaneously in a single experiment by using solutions containing several possible coformers, as well as the ability to access a broad variety of crystal forms without knowledge of solubility phase diagrams.

The studied compounds have previously been investigated in the context of crystal engineering and pharmaceutical cocrystals ${ }^{30-34}$ caf is a widely known central nervous system stimulant, while $\mathbf{x H 2 N s}$ are pharmaceutically active ingredients known to exhibit higher activity than salicylate in the treatment of stress-mediated diseases. ${ }^{35}$ The three hydroxy-2-naphthoic acids, namely 1-hydroxy-2-naphthoic acid (1H2N), 3-hydroxy-2naphthoic acid (3H2N), and 6-hydroxy-2-naphthoic acid $(6 \mathrm{H} 2 \mathrm{~N})$, differ significantly in the geometry of their potential hydrogen-bonding interactions (Scheme 1), and therefore in their solubility and cocrystallization performance.

The caf:xH2N cocrystals were initially investigated using more traditional solution-based methods by Bučar et. al., ${ }^{30}$ who identified and structurally characterized one cocrystal form for each system, each having a 1:1 stoichiometry (Cambridge Structural Database (CSD) reference codes: KIGKIV, KIGKOB, KIGKUH; henceforth referred to for each case as form I). ${ }^{30}$ In the study reported here, we pursued the interfacial cocrystalliza-

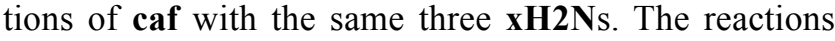
involved the layering of two solutions; one being a saturated solution of caffeine in water (a reasonably good solvent for caf), the second being a nearly saturated solution of $\mathbf{x H 2 N}$ in an organic solvent that is immiscible with water (see SI document) and in which the solubility of the acid is high, while the solubility of caf is low (e.g. non-cyclic ethers, aliphatic alcohols and acetic acid esters). Whereas there is no driving force for crystallization to occur because of the low amount of both coformers simultaneously present in either phase, layering the two solutions allows a cocrystal to precipitate at the interface (Scheme 1) owing to its lower free energy. A coformer concentration gradient at the interface then facilitates slow incorporation of coformer molecules from both sides of the interface to the growing cocrystal. In almost every example reported below, crystals suitable for single crystal X-ray studies were obtained.

\section{Results and discussions}

\section{Effects of solvent choice on cocrystal composition and polymorphic form.}

\subsection{The caf:6H2N cocrystal}

Initial studies focusing on the caf:6H2N system yielded a range of cocrystals of various stoichiometries, as well as new polymorphs and hydrates (Table 1), thus demonstrating the high efficacy of IC in cocrystal screening. Specifically, we were able to reproduce the 1:1 (caf) $\cdot(\mathbf{6 H 2 N})$ cocrystal, initially reported by Bučar et al. (form I; space group $P-1, Z^{\prime}=1$ ) (Fig. 1a), but we also obtained an additional new polymorph of this cocrystal, namely form II (see SI document). Form II crystallizes in space group $P 2_{1} / c$ and its structure is based on discrete 2:2 supramolecular caf:6H2N assemblies, wherein the $6 \mathbf{H 2 N}$ molecules form dimers through $\mathrm{O}$ $\mathrm{H} \cdots \mathrm{O}$ hydrogen bonds via a $R_{2}{ }^{2}(8)$ synthon. The caf molecules are disordered over two positions and are bound to the hydroxyl group of $\mathbf{6 H 2 N}$ through either an $\mathrm{O}-\mathrm{H} \cdots \mathrm{O}$ hydrogen or an $\mathrm{O}-\mathrm{H} \cdots \mathrm{N}$ hydrogen bond via a $D(2)$ synthon (Fig. 1b).

Further IC experiments led to the discovery of a third anhydrous cocrystal form, namely the $2: 1(\mathbf{c a f})_{2} \cdot(\mathbf{6 H 2 N})$ cocrystal (see SI document). The crystal structure of this material is based on discrete three-component caf:6H2N assemblies. In the assembly, one caf molecule is bound to $6 \mathrm{H} 2 \mathrm{~N}$ through an $\mathrm{O}-\mathrm{H} \cdots \mathrm{N}$ hydrogen bond via a $R_{2}^{2}(7)$ synthon, while the second caf molecule is disordered over two positions and bound to naphthoic acid through an $\mathrm{O}-\mathrm{H} \cdots \mathrm{N}$ or $\mathrm{O}-\mathrm{H} \cdots \mathrm{O}$ hydrogen bond (depending on the caf orientation) via a $D(2)$ synthon (Fig. 1d).

Table 1. Solvents used in combination with water to crystallize various caf:xH2N cocrystal forms.

\begin{tabular}{ccc}
\hline $\mathbf{x H 2 N}$ & organic solvent & cocrystal form obtained \\
\hline $\mathbf{6 H 2 N}$ & ButOAC & $1: 1$, form I \\
& EtOAc & $1: 1$, form II \\
& DIPE* & $1: 1$, form III \\
& DIPE/xylene* & $1: 1$, form IV \\
& ButOAC & $1: 1$, monohydrate \\
& DIPE & $2: 1$ \\
& 2-butanone* & $2: 3$, monohydrate \\
$\mathbf{1 H 2 N}$ & EtOAC & $1: 1$, form I \\
& DIPE & $1: 1$, form II \\
$\mathbf{3 H 2 N}$ & EtOAC & $1: 1$, form I \\
& DIPE & $1: 1$, form II \\
\hline
\end{tabular}

* supersaturated solution 
a)

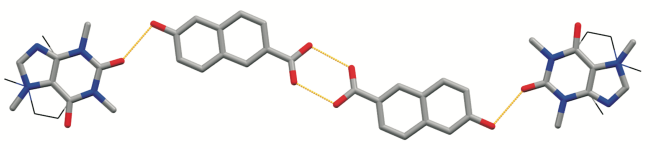

c)

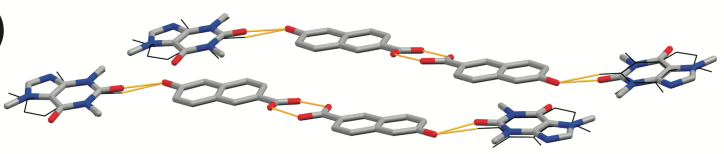

e)

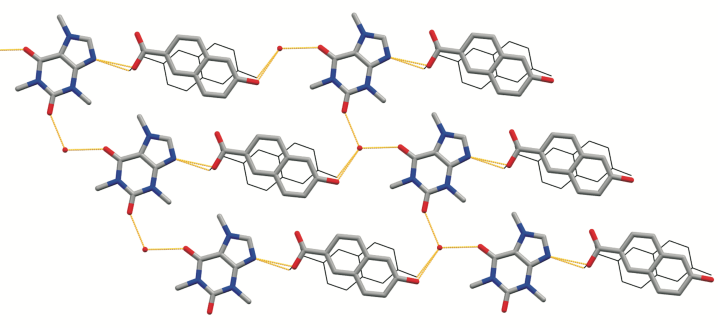

b)

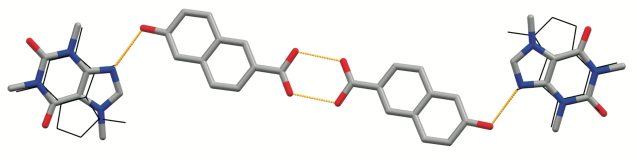

d)
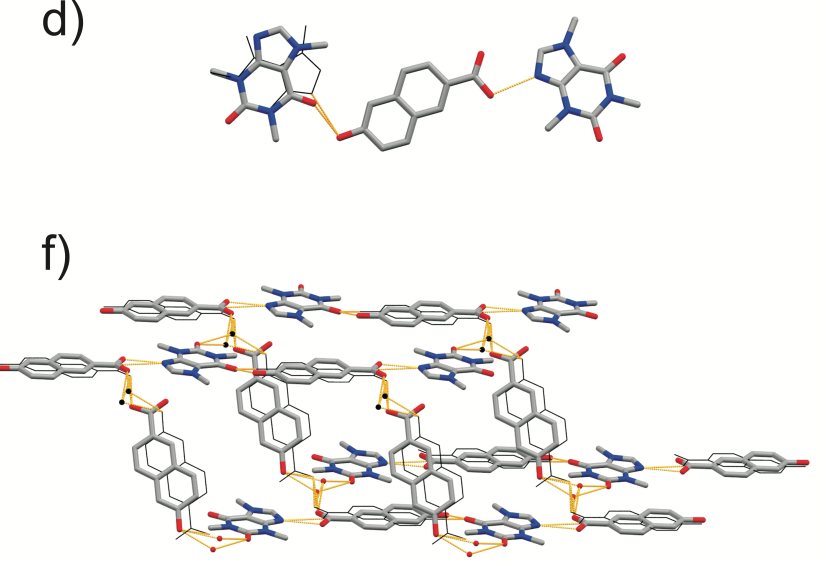

Figure 1. Supramolecular caf:6H2N assemblies in the crystal structures of: a) anhydrous $(\mathbf{c a f}) \cdot(\mathbf{6 H 2 N})$, form I; b) anhydrous (caf) $\cdot(6 \mathrm{H} 2 \mathrm{~N})$, form II; c) anhydrous $(\mathbf{c a f}) \cdot(\mathbf{6 H 2 N})$, form III; d) anhydrous $(\mathbf{c a f})_{2} \cdot(\mathbf{6 H 2 N})$; e) $(\mathbf{c a f}) \cdot(\mathbf{6 H 2 N}) \cdot\left(\mathrm{H}_{2} \mathrm{O}\right)$ monohydrate; f) (caf) $)_{2} \cdot(\mathbf{6 H 2 N})_{3} \cdot\left(\mathrm{H}_{2} \mathrm{O}\right)$ monohydrate. Minor occupation sites (up to $50 \%$ ) of disordered molecules are shown using the "wireframe" display style. Hydrogen atoms are omitted to enhance clarity.

Notably, two hydrated caf:6H2N cocrystal forms were discovered: the $1: 1: 1$ (caf) $\cdot(\mathbf{6 H 2 N}) \cdot\left(\mathrm{H}_{2} \mathrm{O}\right)$ and the 2:3:1 (caf $)_{2} \cdot(\mathbf{6 H 2 N})_{3} \cdot\left(\mathrm{H}_{2} \mathrm{O}\right)$ cocrystal monohydrate. ${ }^{36}$ The crystal structure of the $(\mathbf{c a f}) \cdot(\mathbf{6 H} \mathbf{H}) \cdot\left(\mathrm{H}_{2} \mathrm{O}\right)$ cocrystal monohydrate is based on two-dimensional flat hydrogen-bonded layers. Within the layers, caf and disordered 6H2N molecules are connected by $\mathrm{O}-\mathrm{H} \cdots \mathrm{N}$ hydrogen bonds via $R_{2}^{2}(7)$ synthons. The caf:6H2N molecular pairs are further linked through water molecules by $\mathrm{O}-\mathrm{H} \cdots \mathrm{O}$ hydrogen bonds through $D(2)$ synthons (Fig. 1e). Structural analyses of the $(\mathbf{c a f})_{2} \cdot(6 \mathrm{H} 2 \mathrm{~N})_{3} \cdot\left(\mathrm{H}_{2} \mathrm{O}\right)$ monohydrate revealed that its structure is based on interpenetrated three-dimensional caf:6H2N: $\mathrm{H}_{2} \mathrm{O}$ assemblies. In these structures, caf and 6H2N are linked into molecular chains that are sustained by $\mathrm{O}-\mathrm{H} \cdots \mathrm{N}$ and $\mathrm{O}-\mathrm{H} \cdots \mathrm{O}$ hydrogen bonds via $R_{2}{ }^{2}(7)$ and $D(2)$ synthons. The one-dimensional structure is extended into three dimensions by a disordered pair of 6H2N: $\mathrm{H}_{2} \mathrm{O}$ molecules (Fig. 1f).

It should be noted that it was not possible to obtain reproducibly phase-pure samples of the previously reported anhydrous 1:1 cocrystal (form I) using nearly saturated solutions of the coformers. This form was initially only observed three days after harvesting all (caf) $\cdot(6 \mathbf{H 2 N}) \cdot\left(\mathrm{H}_{2} \mathrm{O}\right)$ crystals at the solvent interface, when a second crop of large single crystals of form I emerged.

The mechanisms leading to the formation of the large variety of caf:6H2N cocrystal forms are not understood at this time. ${ }^{37}$ We do, however, speculate that access to crystal form with a different atypical stoichiometry may be attributed to solubility effects. In particular, we believe that a change from a $2: 1$ to $1: 1$ coformer ratio is likely to be related to the higher solubility of $6 \mathbf{H 2 N}$ in butyl acetate compared to diisopropyl ether, leading to a higher concentration of $6 \mathrm{H} 2 \mathrm{~N}$ at the interface.

\subsection{The caf: $1 \mathrm{H} 2 \mathrm{~N}$ and caf: $3 \mathrm{H} 2 \mathrm{~N}$ cocrystals}

The substantial variety of discovered caf:6H2N cocrystal forms prompted us to extend our studies to the caf:1H2N and caf:3H2N cocrystal systems. A more limited set of experiments soon led not only to the preparation of the previously-known cocrystal phases (Fig. 2a,b), but also to the discovery of a new polymorph of (caf) $\cdot(1 \mathrm{H} 2 \mathrm{~N})$ and $(\mathbf{c a f}) \cdot(\mathbf{3 H} 2 \mathrm{~N})$, referred to as form II (Table 1 and SI document). Form II of (caf) $\cdot(\mathbf{1 H 2 N})$ crystallizes in space group $P 2_{1} / n$ with three caf:1H2N pairs in the asymmetric unit $\left(Z^{\prime}=3\right)$. Each of the pairs is held together by $\mathrm{O}-\mathrm{H} \cdots \mathrm{N}$ hydrogen bonds through $R_{2}{ }^{2}(7)$ synthons, whereby the $\mathbf{1 H 2 N}$ hydroxyl groups are engaged in intramolecular $\mathrm{O}-\mathrm{H} \cdots \mathrm{O}$ hydrogen bonds by a $S$ (6) synthon (Fig. 2a). Form II of (caf) $\cdot(3 \mathbf{H} 2 \mathbf{N})$ crystallizes in space group $P 2_{1} / n$ with one molecule of caf and $3 \mathbf{H} 2 \mathrm{~N}$ in the asymmetric unit $\left(Z^{\prime}=1\right)$. The cocrystal components are also held together by $\mathrm{O}-\mathrm{H} \cdots \mathrm{N}$ and $\mathrm{O}-$ $\mathrm{H} \cdots \mathrm{O}$ hydrogen bonds through $R_{2}^{2}(7)$ and $S(6)$ synthons (Fig. 2b).

It was also established that, in the cases of the caf:1H2N and caf:3H2N cocrystal systems, a change in polymorphic form of the product was achieved by varying the interface conditions, as shown in Table 1. 
a)
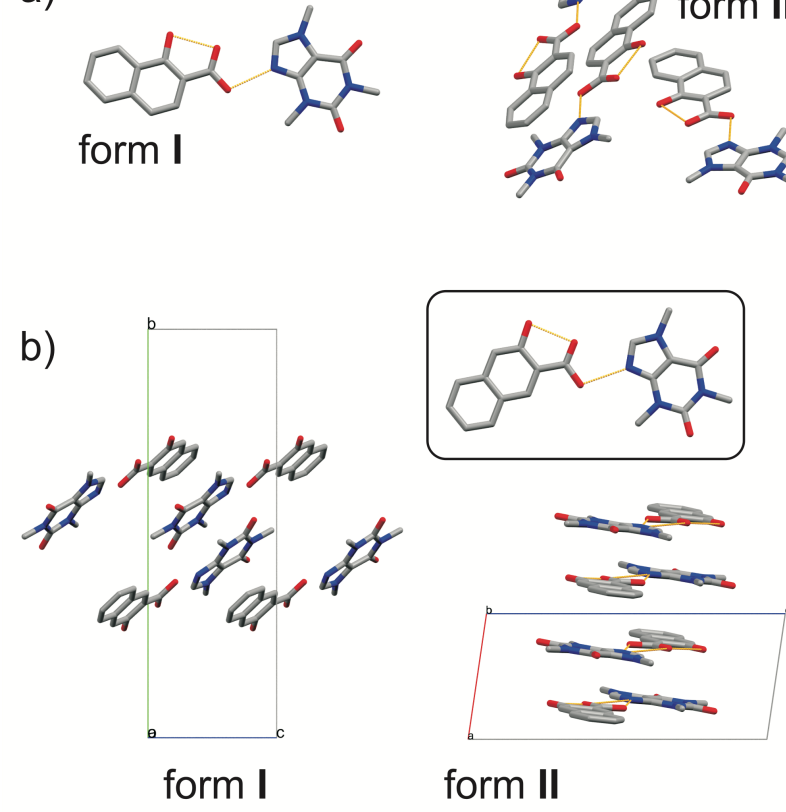

form II

Figure 2. a) Crystallographically independent caf:1H2N assemblies in the (caf) $\cdot(\mathbf{1 H 2 N})$ cocrystal forms I and II; b) Supramolecular caf:3H2N assembly found in the crystal structures of (caf) $\cdot(\mathbf{3 H 2 N})$ forms I and II (highlighted in the rounded rectangle) and crystal packing diagrams of (caf) $\cdot(\mathbf{3 H 2 N})$ forms I and II. Hydrogen atoms are omitted to enhance clarity.

Specifically, the use of more polar solvents favored in both cases the crystallization of form I. That solvent properties can influence the polymorphic outcome of IC processes is not unexpected, ${ }^{9}$ as it mirrors what has been widely reported for conventional solution crystallizations. With specific regard to cocrystal polymorphism, however, it should be noted that problems associated with the precipitation of individual coformers during conventional solution crystallization experiments ${ }^{20}$ are minimised.

\section{Effects of solution concentrations on polymorphic outcome for the caf: $6 \mathrm{H} 2 \mathrm{~N}$ cocrystal}

In an attempt to facilitate the growth of single crystals during the IC experiments, we resorted to the layering of supersaturated solutions of the cocrystal components. Such an approach has not only led to the formation of crystals suitable for single crystal X-ray diffraction studies, but it also enabled, to our surprise, the appearance of new polymorphs. In particular, two new polymorphs of the caf:6H2N cocrystal were discovered, namely forms III and IV (see SI document). These two forms, however, appeared only occasionally and single crystals suitable for structural analyses could be produced only in the case of form III. ${ }^{38}$

Crystallographic analyses revealed that form III crystallizes in space group $P 2_{1} / c$ with three molecules of

both caf and $6 \mathrm{H} 2 \mathrm{~N}$ in the asymmetric unit $\left(Z^{\prime}=3\right)$. The crystal structure is based on two crystallographically independent types of $2: 2$ caf:6H2N assemblies similar to those seen in forms I and II. One is centrosymmetric with disordered 6H2N and ordered caf molecules that are held together by $\mathrm{O}-\mathrm{H} \cdots \mathrm{O}$ hydrogen bonds through $R_{2}{ }^{2}(8)$ and $D(2)$ synthons. The second assembly is noncentrosymmetric and also based on disordered caf and ordered 6H2N molecules, which are sustained by the same types of hydrogen bonds and synthons as those in the the first assembly type (Fig. 1c).

It was also observed that the use of supersaturated solutions of caf and $6 \mathrm{H} 2 \mathrm{~N}$ (using polar solvents) regularely leads to the crystallization of form $\mathbf{I}$ of the caf:6H2N cocrystal, which could not be reliably achieved with the use of nearly saturated solutions (see Table 1 and SI document).

\section{Effects of temperature on cocrystallization kinetics and polymorphic form}

Saturated solutions of caf in water and of the three $\mathbf{x H 2 N s}$ in DIPE were prepared, layered and left for crystallization at a range of different temperatures to monitor the influence of the crystallization rate on the outcome of interfacial cocrystallization. Observations from the resulting IC experiments are summarised in Table 2.

In general, the higher the temperature at which interfacial cocrystallization is performed, the faster a cocrystal is formed at the interface. For instance, the precipitation of the $(\mathbf{c a f})_{2} \cdot(\mathbf{6 H 2 N})$ cocrystal can be accelerated from 2 days to 4 hours by increasing the temperature from $10{ }^{\circ} \mathrm{C}$ to $40^{\circ} \mathrm{C}$. This increase in cocrystallization rate may result from the increased amount of coformer dissolved in solutions at high temperature and/or from increased molecular diffusion rates which facilitate the precipitation process. Accompanying the faster cocrystallization and nucleation processes at higher temperature was a reduction in the particle size of the resulting crystals (see SI document, Figure S2). Low-temperature interfacial crystallizations were, therefore, found to be most appropriate for the growth of large single crystals suitable for structure determination.

Temperature was also observed to have an influence on the polymorphic outcome (Table 2). With the caf:1H2N system, on increasing the crystallization temperature to $40{ }^{\circ} \mathrm{C}$, a mixture of forms I and II was obtained (rather than pure form II, as is seen at lower

Table 2. Effects of temperature on cocrystal formation.

\begin{tabular}{lccc}
\hline $\mathbf{x H 2 N}$ & $\mathbf{1 0}{ }^{\circ} \mathbf{C}$ & $\mathbf{2 0}^{\circ} \mathbf{C}$ & $\mathbf{4 0}^{\circ} \mathbf{C}$ \\
\hline $\mathbf{1 H 2 N}$ & $1: 1$, form $\mathbf{I I}$ & $1: 1$, form $\mathbf{I I}$ & $1: 1$, form $\mathbf{I}+\mathbf{I I}$ \\
& $10 \mathrm{~min}$ & $5 \mathrm{~min}$ & $<1 \mathrm{~min}$ \\
$\mathbf{3 H 2 N}$ & $1: 1$, form $\mathbf{I I}$ & $1: 1$, form $\mathbf{I I}$ & $1: 1$, form $\mathbf{~ I I}$ \\
& $15 \mathrm{~min}$ & $8 \mathrm{~min}$ & $1 \mathrm{~min}$ \\
$\mathbf{6 H 2 N}$ & $2: 1$ & $2: 1$ & $2: 1$ \\
& 2 days & 1 day & 4 hours \\
\hline
\end{tabular}


Table 3. Effects of stirring at room temperature on cocrystal formation.

\begin{tabular}{cccc}
\hline $\mathbf{x H 2 N}$ & solvent & static conditions & stirred solutions \\
\hline $\mathbf{1 H 2 N}$ & DIPE & $1: 1$, form II & $1: 1$, form II \\
$\mathbf{3 H 2 N}$ & DIPE & $1: 1$, form II & $1: 1$, form I \\
$\mathbf{6 H 2 N}$ & DIPE & $2: 1$ & $1: 1$, form I \\
\hline
\end{tabular}

temperatures). We suggest that form II is still the form which precipitates at the interface, and the increased temperature merely increases the rate of conversion to the more stable form $\mathbf{I}{ }^{39}$ This is certainly the case for the caf:3H2N system where form II precipitates at the interface shortly after layering of the two solutions, but at higher temperature undergoes conversion to form I within hours.

\section{Effects of stirring}

The effect of high-speed stirring (at $750 \mathrm{rpm}$ ) during interfacial cocrystallization was investigated for the three caf:xH2N cocrystals using magnetic stir bars (see Table 3). This agitation resulted in the formation of an emulsion of the two immiscible solutions wherein small droplets were created and the curvature of the liquidliquid interface increased. The crystallization rate of each of the cocrystals increased dramatically as a result. Stirring also led to a change in the polymorphic form which was obtained for the caf:3H2N cocrystal, with form I rather than form II being isolated, and a change in the stoichiometry of the caf:6H2N cocrystal form $1: 1$ to $2: 1$. The origins of these polymorphic and stoichiometric variations, which could be based on the increased curvature of the interface, or due to the shear introduced to the system by stirring, is still under investigation.

\section{Competitive coformer studies}

The potential application of IC to screening for cocrystal formation between a compound of interest and multiple putative coformer molecules in a simultaneous manner was investigated by layering a saturated aqueous solution of caffeine and a solution of DIPE saturated with both 1H2N and phenazine. Phenazine, in contrast to $1 \mathrm{H} 2 \mathrm{~N}$, does not possess a carboxylic acid group and was, therefore, not expected to form a cocrystal with caffeine. After combining the two solutions, the known caf:1H2N cocrystal precipitated at the interface. Phenazine did not crystallize either as a pure phase or as a cocrystal with caffeine, thus demonstrating that cocrystallization of caf with a coformer at a solvent interface is not inhibited by the presence of a molecule which does not form a cocrystal.

To investigate a situation where competition between coformer molecules is possible during interfacial cocrystallization a saturated solution of caffeine in water was combined with a solution of DIPE saturated with both 1H2N and 3H2N (the overall molar ratio of caf:1H2N:3H2N was approximately 1:3:3). PXRD indicated that the resulting precipitate at the solvent inter- face contained a mixture of (caf) $\cdot(\mathbf{1 H 2 N})$ form II and (caf) $\cdot(3 \mathrm{H} 2 \mathrm{~N})$ form II (see Figure S1 in SI document).

\section{Summary and outlook}

It has been demonstrated that IC is a tunable and efficient technique to produce a range of multicomponent crystal forms. For the three caf:xH2N cocrystals investigated in this study, IC yielded at least one new cocrystal form for each system. Furthermore, with appropriate control of temperature, solution concentrations, solvent selection and the cocrystallization rate, it was possible to grow single crystals at the interface for all three systems.

Interfacial cocrystallization can be applied to screen quickly and simultaneously for cocrystal formation between a drug molecule and several potential coformer molecules in one crystallization vessel. We have also demonstrated that a cocrystal will readily form at the interface of two immiscible solvents, despite the direct interactions and competition of coformers within the organic solution. The great variety of identified caf:xH2N cocrystal forms obtained, as well as its convenience, establishes the merit of this crystallization method in the context of cocrystal screening and materials discovery.

\section{ASSOCIATED CONTENT}

Supporting Information. Specifics concerning the synthesis of the crystal forms, their crystallographic and microscopic analysis.

Accession Codes. CCDC 1583501-1583507 and 1053238 contain the supplementary crystallographic data for this paper. These data can be obtained free of charge via www.ccdc.cam.ac.uk/data request/cif, or by emailing data_request@ccdc.cam.ac.uk, or by contacting The Cambridge Crystallographic Data Centre, 12, Union Road, Cambridge CB2 1EZ, UK; fax: +44 1223336033.

\section{AUTHOR INFORMATION}

\section{Corresponding Author}

E-mail: d.bucar@ucl.ac.uk,wj10@cam.ac.uk

\section{ACKNOWLEDGMENT}

The authors gratefully acknowledge Dr J. E. Davies for the collection of single crystal X-ray diffraction data. The EPSRC is thanked for funding. DKB gratefully acknowledges University College London for support through a UCL Excellence Fellowship.

\section{ABBREVIATIONS}

EtOAc, ethyl acetate; BuOAc, $n$-butyl acetate; DIPE, diisopropyl ether.

\section{REFERENCES}

1. Morissette, S. L.; Almarsson, Ö.; Peterson, M. L.; Remenar, J. F.; Read, M. J.; Lemmo, A. V.; Ellis, S.; Cima, M. J.; Gardner, C. R. Adv. Drug Deliv. Rev. 2004, 56, 275-300. 
2. Schultheiss, N.; Newman, A. Cryst. Growth Des. 2009, 9, 29502967.

3. Vangala, V. R.; Chow, P. S.; Tan, R. B. H. Cryst. Growth Des. 2012, 12, 5925-5938.

4. Trask, A. V.; Motherwell, W. D. S.; Jones, W. Cryst. Growth Des. 2005, 5, 1013-1021.

5. Sun, C. C.; Hou, H. Cryst. Growth Des. 2008, 8, 1575-1579.

6. Maeno, Y.; Fukami, T.; Kawahata, M.; Yamaguchi, K.; Tagami, T.; Ozeki, T.; Suzuki, T.; Tomono, K. Int. J. Pharm. 2014, 473, 179-186.

7. Duggirala, N. K.; Perry, M. L.; Almarsson, O.; Zaworotko, M. J. Chem. Commun. 2016, 52, 640-655.

8. Aitipamula, S.; Chow, P. S.; Tan, R. B. H. CrystEngComm 2014, 16, 3451-3465.

9. Corpinot, M. K.; Stratford, S. A.; Arhangelskis, M.; AnkaLufford, J.; Halasz, I.; Judas, N.; Jones, W.; Bučar, D.-K. CrystEngComm 2016, 18, 5434-5439.

10. Bučar, D.-K.; Lancaster, R. W.; Bernstein, J. Angew. Chem. Int Ed. 2015, 54, 6972-6993.

11. Friščić, T.; Trask, A. V.; Jones, W.; Motherwell, W. D. S. Angew. Chem. Int. Ed. 2006, 45, 7546-7550.

12. Lu, E.; Rodriguez-Hornedo, N.; Suryanarayanan, R. CrystEngComm 2008, 10, 665-668.

13. Trask, A. V.; Jones, W., Crystal Engineering of Organic Cocrystals by the Solid-State Grinding Approach. In Organic Solid State Reactions, Toda, F., Ed. Springer Berlin Heidelberg: Berlin, Heidelberg, 2005; pp 41-70.

14. Zhang, G. G. Z.; Henry, R. F.; Borchardt, T. B.; Lou, X. J. Pharm. Sci. 96, 990-995.

15. Bučar, D.-K.; MacGillivray, L. R. J. Am. Chem. Soc. 2007, 129, 32-33.

16. Bučar, D.-K.; Henry, R. F.; Lou, X.; Borchardt, T. B.; Zhang, G. G. Z. Chem. Commun. 2007, 525-527.

17. Rodríguez-Hornedo, N.; Nehm, S. J.; Seefeldt, K. F.; PagánTorres, Y.; Falkiewicz, C. J. Mol. Pharm. 2006, 3, 362-367.

18. Sheikh, A. Y.; Rahim, S. A.; Hammond, R. B.; Roberts, K. J. CrystEngComm 2009, 11, 501-509.

19. Shah, S.; Maddineni, S.; Lu, J.; Repka, M. A. Int. J. Pharm. 2013, 453, 233-252.

20. Eddleston, M. D.; Sivachelvam, S.; Jones, W. CrystEngComm 2013, 15, 175-181.
21. Bučar, D.-K.; Filip, S.; Arhangelskis, M.; Lloyd, G. O.; Jones, W. CrystEngComm 2013, 15, 6289-6291.

22. Friščić, T.; Jones, W. Cryst. Growth Des. 2009, 9, 1621-1637.

23. Hasa, D.; Schneider Rauber, G.; Voinovich, D.; Jones, W. Angew. Chem. Int. Ed. 2015, 54, 7371-7375.

24. Bučar, D.-K.; Henry, R. F.; Zhang, G. G. Z.; MacGillivray, L. R. Cryst. Growth Des. 2014, 14, 5318-5328.

25. Kadota, K.; Shirakawa, Y.; Matsumoto, I.; Shimosaka, A.; Hidaka, J. Adv. Powder Technol. 2007, 18, 775-785.

26. Tanaka, M.; Yamanaka, S.; Shirakawa, Y.; Shimosaka, A.; Hidaka, J. Adv. Powder Technol. 2011, 22, 125-130.

27. Douaire, M.; di Bari, V.; Norton, J. E.; Sullo, A.; Lillford, P.; Norton, I. T. Adv. Colloid Interface Sci. 2014, 203, 1-10.

28. Yang, H.; Rasmuson, Å. C. FFE 2015, 385, 120-128.

29. Dey, K.; Pal, M.; Rout, K. C.; Kunjattu H, S.; Das, A.; Mukherjee, R.; Kharul, U. K.; Banerjee, R. J. Am. Chem. Soc. 2017, $13913083-13091$.

30. Bučar, D.-K.; Henry, R. F.; Lou, X.; Duerst, R. W.; Borchardt, T. B.; MacGillivray, L. R.; Zhang, G. G. Z. Mol. Pharm. 2007, 4, 339-346.

31. Bučar, D.-K.; Day, G. M.; Halasz, I.; Zhang, G. G. Z.; Sander, J. R. G.; Reid, D. G.; MacGillivray, L. R.; Duer, M. J.; Jones, W. Chem. Sci. 2013, 4, 4417-4425.

32. Madusanka, N.; Eddleston, M. D.; Arhangelskis, M.; Jones, W. Acta Crystallogr. Sect. B 2014, 70, 72-80.

33. Bučar, D.-K.; Henry, R. F.; Duerst, R. W.; Lou, X.; MacGillivray, L. R.; Zhang, G. G. Z. J. Chem. Crystallogr. 2010, 40, 933-939.

34. Bučar, D.-K.; Henry, R. F.; Lou, X.; Duerst, R. W.; MacGillivray, L. R.; Zhang, G. G. Z. Cryst. Growth Des. 2009, 9, 1932-1943.

35. Jeong, K.-w.; Ku, J.-m.; Park, M.-w.; Park, S.-m.; Yang, J.-e.; Nam, T.-g. Chem. Pharm. Bull. 2013, 61, 740-746.

36. The $(\mathbf{c a f})_{2} \cdot(\mathbf{6 H 2 N})_{3} \cdot\left(\mathrm{H}_{2} \mathrm{O}\right)$ cocrystal hydrate formed together with a 6H2N hemihydrate. See the SI document.

37. Bučar, D.-K. Cryst. Growth Des. 2017, 17, 2913-2918.

38. The crystal structure of form IV of the (caf) $\cdot(\mathbf{6 H 2 N})$ cocrystal is under investigation by powder X-ray diffraction and solid-state NMR analyses using a phase-pure sample that was obtained from a melt. The results of these investigations will be published elsewhere.

39. The relative stability of forms I and II of (caf) $\cdot(\mathbf{1 H 2 N})$ was established in competitive slurry experiments. 


\section{For Table of Contents Use Only}

\section{Crystallization at Solvent Interfaces Enables Access to a Variety of Cocrystal Polymorphs and Hydrates}

Stefan J. Diez, Mark D. Eddleston, Mihails Arhangelskis, Marie Milbled, Matthias Müller, Andrew D. Bond, Dejan-Krešimir Bučar and William Jones

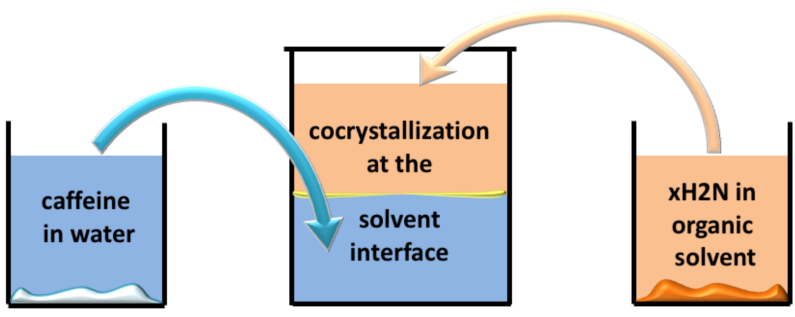

Interfacial cocrystallization is demonstrated to be a simple, yet highly effective, method for the preparation of cocrystals. The crystallization method is based on the formation of a liquid-liquid interface between two immiscible solutions of cocrystalforming compounds, in this case caffeine and hydroxy-2-naphthoic acids. This contribution highlights the discovery of numerous cocrystal polymorphs and hydrates, whereof some exhibit unanticipated compositions. 